\title{
A Study on Effectiveness of Vocabulary Apps---Based on MALL Theory
}

\author{
Chengyuan Wu, Xiaoxu Chen* \\ Zhejiang Ocean University, Zhoushan, China
}

*Corresponding Author: Xiaoxu Chen, Zhejiang Ocean University, Zhoushan, China

\begin{abstract}
Nowadays, with the advent of the mobile phone, we have relished the convenience in many aspects. The emergence of MALL theory contributes to the enhancement of autonomous learning. The traditional way of cramming method can no longer serve students' need anymore. Hence, many students gradually use smart phones as an convenient source of knowledge after class. This empirical study aims to analyze the effectiveness of vocabulary apps on smart phones with scientific data and offer suggestions to the improvement of both vocabulary apps and students.
\end{abstract}

Keywords: MALL, Effectiveness, Vocabulary Apps, Autonomous learning

\section{INTRODUCTION}

When we talk about how to study English, we usually divide it into reading, writing, listening and speaking. However, it is impossible to do well without vocabulary. Vocabulary is a basic element for second language acquisition. Although, according to linguistics, morpheme are regarded as the smallest parts functioning the most importantly, starting with abstract morphemes is difficult and unrealistic. Wilkins (1972) put stress on vocabulary by saying that "Without grammar very little can be conveyed, and without vocabulary nothing can be conveyed." So far, in order to command a better mastery of vocabulary, more and more vocabulary methods have been generated, be they traditional or innovative.

The past decades have witnessed the golden time of the computers when professionals and teachers combined them with vocabulary teaching and learning, which developed the theory called CALL. Teacher applied this novel teaching method in the class. However, CALL merely enhanced the efficiency of study during the class. Therefore, with the advent of mobile technology, studying without the restriction of places and time make the long-life learning and self-study possible, and the branch of CALL - MALL has obtained its reputation. MALL (Mobile Assisted Language Learning) refers to learning the language with the aid of mobile devices, such as phones, MP3, MP4, Pads and so on.

When the study gets rid of the confinement of time and space, it will show the greatest potential. In 2012, the notion of "Internet Plus" was first put forward by Yu Yang, the President and CEO of Analysys International. In march of the same year, premier Li Keqiang has proposed the "Internet plus" action plan for the first time when he reported on the work of the government at the third session of the 12th National People's Congress. The "Internet Plus Education" indicates the combination of Internet platform and educational resources, creating and developing a new ecology of education (Heguang Ping\&Yali Du, 2016).MOOCS (Massive Open Online Courses) is a typical case of the applications. The promise of MOOCs is that they will provide free cutting- edge courses to all users, which could drive down the cost of university-level education and potentially disrupt the existing models of higher education (HE). This has encouraged elite universities to put their courses online by setting up open learning platforms (Li Yuan \& Stephen Powell, 2013). Now, using MOOCS as the complementary material in spare time has become a common phenomenon among college students.

Many years ago, the phones connecting to the internet could function as well as computers. It showed the tendency that the smart phones having taking place of computers little by little. Today, nearly 
everyone has a smart phone. With the characterization of mobility, convenience and multifunction, people choose to use it for entertainment, work and study. According to the survey in 2006(Junbo MA,2007), it showed that there were 1.3 million mobile users in China, let alone in 2019.Mobile devices become a necessity among young digital generations. Therefore, the popularity of mobile devices leads to a theoretical transition from CALL to MALL by scholars at home and abroad .It has been foreseen that the field study with the assistance of mobile devices has unpredictable potential. (Kukulska-Hulme, 2006)

In China,it is a universal phenomenon that students, who are not being allowed to use computers or digital equipment ,memorize the vocabulary by rote. Compared with them, college students can avail themselves of mobile phones, Pads, laptops, etc. Thanks to their flexibility, accessibility and convenience, some vocabulary apps have become a massive hit in domestic market. A multitude of non-English majors desire to get further education, but most of them are hindered by English test. Unlike English major students, they have limited time and opportunity to study and practise English in class, which makes vocabulary learning a more demanding task.

Therefore, it is imperative to develop the capacity of self-learning. For this purpose, the whole paper will discuss the effectiveness of vocabulary apps on the smart phones based on MALL Theory.

\section{BACKGROUND}

\subsection{Domestic Study}

Introduced from the western country, MALL has captured the attention of a host of scholars and has been perfected step by step. From 2004 to 2014, 30 relevant pieces of papers could be searched on CNKI, among which the theory related to mobile learning and educational psychology accounts for 70\%.It was Han Ling who first published the article about the combination of mobile education and English teaching, coming up with the five basic formation of mobile English teaching(Chajuan Hu\&Chunlei Shen,2004).Later, Gao Min, Wu Jiejun and Yao Jinghong explored M-Learning deeper than Han Ling, because they attempted to design the system for mobile English learning in 2008.(Chajuan Hu\&Chunlei Shen,2004).In some cases, mobile learning is one of the branches of autonomous learning, which totally depends on the students. Therefore, the monitor of study involves two aspects_ courseware and evaluation of the effectiveness (Min Gao\&Jiejun Wu \& Jinghong Yao, 2008).And Yang Lifang made great efforts, applying the mobile system to vocabulary study. Supported by the theory of Dual Coding Theory, Working Memory Theory, the vocabulary learning model with smart phones should be put into practice(Yang Lifang,2012).As an emerging research focus, most of the MALL researches are not integrated with boarder theoretical basis. And they are lack of quantifiable statistics to convince readers. Even if they did set the experimental group and control group, the data were measured by students' subjective feelings, which rendered the result inaccurate. Besides, university students are the main research objects, which are more than pupils, high school students and adults. Worse still, only 2 papers mentioned MALL theory, which means it is still a new area to be further studied in China (HeBin Xu\&He Zhao, 2015).

Therefore, the trend of future study is explicit. The scientists and experts ought to integrate more theory together with more reliable data of the research. And they can design different researches which can distinguish students' ability in different aspect.

\subsection{Overseas Study}

In1980s, affected by behaviorism, CALL theory emerged. Since the outset of 21century, numerous devices with smaller size and more comprehensive functions has been invented and gradually developed. And the concept of MALL theory was born at that time. These devices were not originally designed to assist vocabulary study, but now they were used to, directly and indirectly, be applied in the language learning. Outdated as it is, the first mobile language experiment was conducted in the Stanford Learning Lab by using email and voice. (Junbo MA, 2007).However, the computers are inconvenient to carry everywhere and people used it with the limitation of time and places. Even when the laptops that were lighter and more portable, the problem didn't completely be solved. MALL prevails later than CALL and has a short period of development, so the materials and essays maybe less than CALL which can be referred.

The western countries preceded us on the research of MALL a lot. Although a great number of 
publications collected over the past decades can be found on the internet, the paper with scientific solutions of learning is still far between and needs more efforts to be paid. Confronting with the same problem with Chinese scholars, they found the scanty of the reliable data due to the research enduration and lack of enough participants involved.(Jack Burston,2014) After the collection and analysis of studies, it showed striking fact that the number of studies which had detailed outcomes was less than 20.(Derya Bozdogan,2015).

The domestic scholars have been simultaneously conclude and reflect on the studies at home. Apart form that, they are currently analyzing the result from other countries. The conclusion can be drawn from the statistics between2000-2015 that on the one hand, main research on MALL is related to Pedagogy and Linguistics (FeiLong Jing\&Jie Qin2018); on the other hand, MALL turn infancy into maturity and was isolated from CALL, opening up an innovative area.(Kukulska-Hulme \&Shield,2008).

\subsection{Autonomous Learning}

When the need and result can't be satisfied during the class, learning by oneself is indispensable. According to the requirement of China's Education Ministry (2007) for college English teaching, it is necessary for both teachers and students that they should fully use the the advanced communication technology in the study. Teacher shouldn't be in a dominant place to entirely decide students' learning activities. In other words, students are requested to choose suitable learning materials, searching for the optimum ways, and acquire the abilities of self-regulated learning under the instructions.(Zhimei lei,2018). What has changed in recent years is the transformation from passive study to active study.(Scott G\&Alison H.,2001)Self-regulated learning does play an important role in second language acquisition. Generally, it can be divided into planning strategies, monitoring strategies and regulation strategies. In other words, it involves one's motivation, study process and the effectiveness. In a way, metacognitive is similar to self-regulated. With higher motivation, students can achieve his/her goals by setting an appropriate goal with perseverance.

Nonetheless, when using mobile devices, most students aren't able to accomplish their goals that they speculated before. Hence, it is sensible to figure out students learning process with self-regulated learning.

\section{RESEARCH PROCESS}

\subsection{Research Objects}

All of the participants are all non-English major students who used and are using vocabulary apps. And they are undergraduates of different universities in China.

\subsection{Research Hypothesis}

This questionnaires comprise thirteen questions in 4 parts.

- gender, grade, education background

- habits of using the vocabulary apps

- their purpose, process and result

- $\quad$ some suggestions

\subsection{Research Method}

In order to get the data as reliable as possible, this study gave out the questionnaires consisting of 13 questions via the Internet and was analyzed with SPSS.

The design of the questions can be divided into 4 parts. First, their basic information, including gender, grade and university (whether they study in prestigious universities or not) to figure out if there are some discrepancies among the factors. Second, the habits about their daily use of Apps. This part is designed to know their using frequency, time that they spend and amount of vocabulary they plan to learn. Third, the aim of this section is to discover their intentions, views and results on the selflearning with mobile devices. The options are totally disagree, disagree, just so so, agree and totally agree, which stand for 1-5 point respectively. With SPSS, the results can reflect the correlation 
between them. Last, their suggestions to improve the App.

The author gave out the survey "A Study on Effectiveness of Vocabulary Apps---Based on MALL Theory" on April $16^{\text {th }}$.The survey ended on April 23th.It distributed 500 questionnaires and received 450 questionnaires. The research objects are all non-English majors from various nationwide universities, who used and are using prevalent vocabulary Apps. More than half of the participants are from Zhejiang Province (54.89\%), and the the number of females $(74.89 \%)$ are nearly three times more than that of males $(25.11 \%)$.

SPSS was used to help analyze the relevance among the factors. And the proposals were sorted out to perfect the vocabulary apps.

Three sections constitute the findings — Habit of the vocabulary apps; The status quo of using vocabulary apps; The advice on improving the usage of vocabulary apps.

\section{FINDINGS}

\subsection{Habit of the Vocabulary Apps}

450 participants joined the research. And $80.22 \%$ of them are using different vocabulary apps. The number of female, which accounts for $74.89 \%$, is more than the number of the male. It means female shows greater tendency to use vocabulary apps. And sophomores and juniors are the main force of using vocabulary apps. From freshmen to senior students, the number of using forms inverted U curve and reaches its peak at junior (44.44\%).Compared with prestigious universities, such as Peking University or Tsinghua University, the majority of students $(92.67 \%$ ) are not from prestigious universities. In the key institutions, students enjoy a stronger academic atmosphere, forming his/her own learning skill.

Although lots of people are taking advantage of this convenient method to learn vocabulary, students can seldom keep it a habit to use the apps everyday. They said they might be distracted by the other apps. It is obvious that only when they adhere to the goals and not distracted by other things can they achieve better. (Rachel J.Ebner \& Linnea C.Ehri, 2013)Moreover, many participants tend to spend less time memorizing a few words. The result can present the fact that they tend to recite 50 new words within half an hour. Non-English majors still have some trouble learning English without awareness of the significance of vocabulary. They are still reluctant to make full use of enough time to study the words. And non-English majors lack the habit of routine reading and learning, hence they are unfamiliar with some fundamental words, which means it will take them more time and effort to enrich their vocabulary, keeping the pace with the English majors.

Figure1: The Correlation between daily use and users

\begin{tabular}{|l|l|l|l|}
\hline & Gender & Grade & Education Background \\
\hline Using vocabulary apps or not & 0.924 & 0.897 & 0.83 \\
\hline Using everyday or not & 0.966 & 0.359 & 0.607 \\
\hline The number of vocabulary memorizing & 0.495 & 0 & 0.116 \\
\hline The duration of using vocabulary apps & 0.231 & 0 & 0.261 \\
\hline$* \mathrm{p}<0.05 * * \mathrm{p}<0.01$ &
\end{tabular}

From SPSS data, we can conclude that there is no intrinsic correlation between daily use and gender or education background. The correlation coefficient is close to 0 and $\mathrm{P}$ value is above 0.05 . One the one hand, it demonstrates that both males and females shared the same experience, that is to say, there have made no differences in learning vocabulary on mobile phones. Females seem to have different using habits from males. On the other hand, whether a student studies in a prestigious university or not, in effect, doesn't influence one's daily use of vocabulary apps a lot. It even shows the negative correlation. The more prestigious one studies in, the less possibility of using vocabulary apps a lot. Therefore, these two eternal factors have nothing to do with their habit.

Nevertheless, students from different grades do affect their using habit. The correlation coefficient between "grade" and "the number of vocabulary memorizing","the duration of using vocabulary apps" are $0<0.01$, which illustrate the strong and positive correlation .In the first year, students might belittle themselves and had little confidence in self-learning. At that moment, they didn't cultivate an interest in English. But as they climb to higher grades, the ability of English has been improved as 
well. Students also obtain richer vocabulary and more clearly understanding of their thirsty for knowledge. The higher grade they are in, the more they know to manage the time and to design the plan.

In short, we need to explore the deeper cause which impact directly on their behavior and habit.

\subsection{The Status Quo of Using Vocabulary Apps}

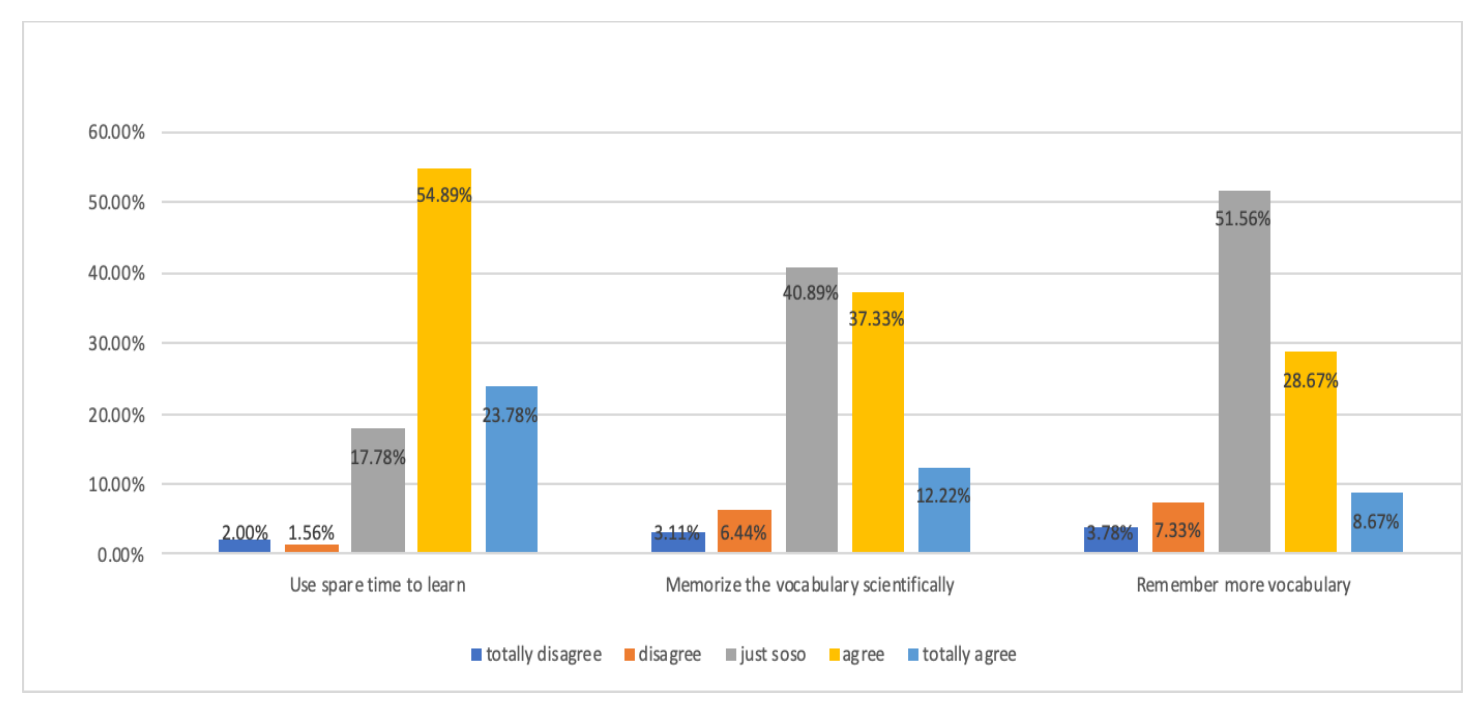

Figure2: Participants'views on vocabulary apps

A multitude of reference books instructing students to learn vocabulary have been sold in the book stores, vocabulary apps are still attractive to young people. More than half of the participants (54.89\%) agree that they can avail themselves of the spare time to learn the new words. When they are waiting in line or on public transportation, it's a good choice to kill the time and learn some new words. And obviously, smart phones enjoy the advantage of lighter weight, which means portable and easily mobile. However, in contrast with reference book, it doesn't appear that students $(40.89 \%)$ think highly of that using vocabulary apps have merit of scientific way to remember the words better. Some of them complained that the part of reviewed words took them some time and the interest and patience to study the new words chopped. Only a minority of students $(8.67 \%)$ totally agree the striking improvement of the vocabulary acquisition. It might explain the reason why the students tend to use fragmented time rather than a big chunk of time to study the word.

Just mentioned in the first part, the outer factors have little relevance to the using habit and the result. Consequently, the inner factors should be considered. A large number of experiments have been conducted by the scholars, they just put one variant or one factor into consideration. However, the metacognition were put forward several decades ago and won the fame in educational psychology. The planning, monitoring and regulation strategies constitute the theory. In other words, the purpose, process and effectiveness with feedback or adjustment are all of consequence, thereby table 2 mainly deal with the connection among them. The data bring to light many direct correlation among 3 inner factors.

Figure3: The correlation among user's motivation, process and effectiveness

\begin{tabular}{|c|c|c|c|c|c|}
\hline & & $\begin{array}{l}\text { The purpose of } \\
\text { using vocabulary } \\
\text { apps }\end{array}$ & $\begin{array}{l}\text { The habit } \\
\text { of using }\end{array}$ & $\begin{array}{l}\text { The methods of } \\
\text { memorizing the } \\
\text { words }\end{array}$ & $\begin{array}{l}\text { The } \\
\text { effectiveness of } \\
\text { using }\end{array}$ \\
\hline \multirow{2}{*}{$\begin{array}{l}\text { The purpose } \\
\text { of using } \\
\text { vocabulary } \\
\text { apps }\end{array}$} & Correlation Index & 1 & & & \\
\hline & $\begin{array}{l}\text { Pearson } \\
\text { Correlation } \\
\text { Coefficient }\end{array}$ & & & & \\
\hline \multirow{2}{*}{$\begin{array}{l}\text { The habit of } \\
\text { learning }\end{array}$} & Correlation Index & $0.543 * *$ & 1 & & \\
\hline & $\begin{array}{l}\text { Pearson } \\
\text { Correlation } \\
\text { Coefficient }\end{array}$ & 0 & & & \\
\hline The methods & Correlation Index & $0.429 * *$ & $0.460 * *$ & 1 & \\
\hline
\end{tabular}




\begin{tabular}{|c|c|c|c|c|c|}
\hline $\begin{array}{l}\text { of } \\
\text { memorizing } \\
\text { the words }\end{array}$ & $\begin{array}{l}\text { Pearson } \\
\text { Correlation } \\
\text { Coefficient }\end{array}$ & 0 & 0 & & \\
\hline \multirow{2}{*}{$\begin{array}{l}\text { The } \\
\text { effectiveness } \\
\text { of using }\end{array}$} & Correlation Index & $0.438 * *$ & $0.511 * *$ & $0.567 * *$ & 1 \\
\hline & $\begin{array}{l}\text { Pearson } \\
\text { Correlation } \\
\text { Coefficient }\end{array}$ & 0 & 0 & 0 & \\
\hline
\end{tabular}

Apparently, all the $\mathrm{p}$ value $<0.01$ and the correlation index $>0$, which means all these factors are closely connected and have direct connections. According to the questionnaire, a quantity of students hold that the purpose of achieving higher grades is equal to the purpose of improving themselves. Nearly half of the students, respectively $45.78 \%$ and $43.11 \%$, agree that they want to enrich their words and obtain many English certifications to have a better promotion in the future career. By contrast, there are still a minority of participants admit the perseverance of routine study satisfy their sense of achievement that they enjoy a lot. From the Figure3, we can learn one's purpose has various impact on the method he/she uses to study the vocabulary. The correlation coefficient between the purpose and the effectiveness is 0.438 . It means that the high motivation over a long period determines the substantial vocabulary size. (Norbert Schmitt, 2008)

Being different from Chinese characters, English words tend to convey the emotions. Namely, they involves many meanings, varying with the different and specific situations. It's impossible and irrational to grasp the whole meaning. When learning them, some students are apt to keep most of the meaning in mind, others choose the frequent use to memorize. In the end, they get different results.

No one can efficiently have a good command of the language in a traditional and mechanical way. Continual repetition of the vocabulary and its meaning not only consumes more time, but also harvests less. Therefore, learning vocabulary on apps help us memorize the words firmly with many scientific and interesting solutions. Usually, there is a picture beside the new word. For instance, if you learn the word "relish", the picture is about some young teenagers who are lying on the beach, enjoying the sunshine. The picture is informative and impressive, which combines the word with image together. Based on the theory of multimodel learning environment, the methods of representing the massage exert the influence on the study result differently. (Siying Li\&Yuan Gao, 2016)In addition, $48.22 \%$ of the participants maintain that studying the new words in sentences, even in the articles helps shape a stronger memory of the vocabulary. Dating back to the time when we were in primary school, we grasp the new Chinese characters automatically after finishing the text in the book. In a specific context and situation, we naturally understand the meaning of the word and know how to use it. Besides, Chinese radicals have the same function as roots and affixes, facilitating both the tense and efforts. And students revealed the preference for the vocabulary apps if the lock screen can also be accessed. The $\mathrm{p}$ value indicating the correlation between the methods and the effectiveness is $0<0.01$. We can conclude that the utilization of appropriate way contribute to the great effectiveness of the result.

However, although their quantity of vocabulary are able to proliferate in a short term, long time acquisition still necessitate the greater and further effort to pay.3.33\% of the students think there is no distinction between the assistance of paper books and vocabulary apps.

\subsection{Suggestions}

Vocabulary apps is a double-edged sword rather than a panacea. It can assist us in self-learning but it doesn't work all the time with all the people. From the analysis, the feedback that validness of short term memory and preference of the paper books by someone still accounts for a small number of the statistics, which we still should be put a premium on. Accordingly, it's indispensable to make improvement both on vocabulary apps and autonomous learning.

\subsubsection{Suggestions on Vocabulary Apps}

\section{- Supplement with More Vocabulary Information}

When we study the Chinese Characters, teachers impart sufficient information to us to make a better understanding. The more information they offer, the more proficiently we can use. It can also be applicable to English. Differing with Chinese, English words observe their own rules in particular 
ways, words change slightly when transformed into nouns, verbs, adjectives or even adverbs in different variants. We can draw an analogy between vocabulary and a string of grapes. Rather than learning the words separately, it's advisable to combine several words together in a regular way with an invisible string. When the new words is showed, its variants, synonyms, antonyms and set phrases should also be showed. The participants stated that they could recognize the word in its original form, but failed to write or even discern what is its adjective form. Only when we don't learn the words in an isolated way can we totally use them. Hence, the vocabulary apps ought to explain the words and their other forms simultaneously.

\section{- Improvement of Vocabulary Learning Methods}

BaiCiZhan is a typical vocabulary app renowned for its striking feature with some vivid pictures. Each word is given with the relative image. Because of its interesting and funny pictures, it saves students time to study more new words. Nonetheless, it's a universal phenomenon that what they literally bear in mind is the picture instead of the word itself. They are not able to recall the meaning independent of the image.

Using the method called Homophonic Memory is also dependable. For instance, the English word "pond" has a similar pronunciation with "pang de" in Chinese (an adjective, fat). The Vocabulary apps will help you to memorize in this way, "Yi ge pang de ren diao dao chi tang li(A fat man fell into the pond.)."The similar sound functions similarly with pictures, making you laugh with nothing left in your mind.

But the techniques provided by vocabulary apps are definitely not without a single redeeming feature. The one of the imperative measures is to present some more efficient tips to the users. The definitions of the significant words used frequently should be highlighted with some set phrases in the context or sentences. What is more advisable is to examine the words in comprehensive ways. For instance, the vocabulary can weekly provide the users a short passage including the words learned in this week to check whether they can recognize them and understand the meaning.

\section{- The Necessity of Rewards}

A quantity of vocabulary apps will present a calendar recording the days of your learning. The more persistent you are, the more records you can get. Some people view it as the certification of hard work, posting the records on the social media. But this kind of reward can't result in a long-term perseverance. In addition, some people show more interest in the apps which will give grant a refund, as long as the customers guarantee to use it everyday. If they forget to sign in and use it one day, refund will not be able to achieved. In this regard, users can kill two birds with one stone, that is, keeping a good habit of perseverance as well as building the vocabulary. For the sake of money, they'll use it on their own initiatives. Many participants suggest that the daily records should be transformed into credits, which can be converted into other rewards, such as English original books, stationery and so on.

\subsubsection{Suggestions on the Non-English Majors}

\section{- Enhancement of Self-Regulation}

Taking into all the factors analyzed into consideration, the self-regulation partly contribute to the efficient study. The emphasis on the lifelong learning request us to develop the capacity of studying on our own.

For the purpose of better autonomous learning, firstly, try to figure out the incentive. Namely, make your motivate clearly. Many students give more priority to pass the exam than other reasons. The more higher the aim is, the more motivated they are, be it for the test or something else.

Secondly, make a realistic plan and resist the temptation. With the unscientific plan, students also fail to memorize the words. They are inclined to overvalue or undervalue themselves. As a consequence, they have no idea how to make an effective and concrete plan. Writing down "I will memorize 50 new words every day." on paper, they don't know whether they can gain more or not. Before that, it here is an need to evaluate your vocabulary level on Internet. Besides, the other entertainment functions of the mobile phone may interfere with the study. They may find excuse to exempt them from sense of guilt if they doesn't finish the plan. Thus, do your best to resist the seduce and focus on the study, 
which is of the utmost importance.

Thirdly, remember to monitor the process and the result. While learning, you need to examine the effectiveness regularly. Once you find that spending amounts of time results in low efficiency, try to modify the plan as well as the method and search for another way to facilitate your study.

\section{- Collaborative Learning}

Autonomous learning, a difficult demand for a heap of students, isn't identical to studying alone without getting supports from others, so it's feasible to study with some groups. Since students are lack of self-discipline, collaborative learning functions well under some conditions. With so many people supervising mutually, students can access to the feedback, supports and advice from the mates. In that atmosphere, they are less likely to be distracted by other things and are more preoccupied with the target.

Try to find the group whose members share the same goal. People always cooperate with others, striving for the same target. If you are in trouble, do not hesitate to ask them for some help.

\section{CONCLUSION}

After the whole research, the following conclusion can be reached: there are dual factors - the external one and the internal one, which exert impact on students' vocabulary learning. The environment and the background are the driving forces to stimulate the motivation. And the individuals who differ in language aptitudes, use of strategies, personality and even the time and efforts they spend will lead to different attainment (Weidong Dai, 2013). Although the application of Mobile Assisted Language Learning in vocabulary didn't display the optimal effect, it did function well to facilitate non-English majors' autonomous learning. Besides, the connections among these factors were found during the experimental process.

This tentative study still need to be improved and further studied. Options of the questionnairetotally disagree, disagree, just so so, agree and totally agree sometimes are too vague for students to discern the discrepancies among them, impacting on the choice to some extent. Besides, the single use of questionnaire is one-sided. In the future study, they can make comparative study by testing the participants and contrasting with the grades. In addition to the questionnaire, the result will be more detailed if the interviews or observations is added. (Zengning HU, 2013)

There is still long way to go for MALL. With the development of pedagogy, more and more countries have reached the consensus that long-life learning as well as autonomous learning is conductive to both the people and the society. It can not only improve the quality of people's life, but accelerate the development of the society (Jianjun Feng, 2007) Therefore, we need to fully avail ourselves of the mobile devices to make our study as comprehensive and efficient as possible.

\section{REFERENCES}

[1] Zhimei Lei. Vocabulary Learning Assisted with Smart Phone Application[J].Theory and Practice in Language Studies(11):1511-1516.2018.

[2] Zengning Hu.Vocabulary Learning Assisted by Mobile Phones:Perceptions of Chinese Adult Learners.[J]Journal of Cambridge Studies(8):138-154.2013.

[3] Norbert Schmitt.Review Article:Instructed second language vocabulary learning[J].Language Teaching Research(3):329-363.2008.

[4] Jake Burston.Twenty years of MALL project implementation: A meta-analysis of learning outcomes[J].ReCALL(1):4-19.2014.

[5] Derya Bozdogan.MALL Revisited:Current Trends and Pedagogical Implications[J]. Procedia-Socia and Behavioral Science(195):932-939.2015.

[6] Weidong Dai. A New Concise Course in Linguistics for Students of English[M]. Shanghai : Shanghai Foreign Language Education Press. 2018.

[7] Li Yuan \& Stephen Powell. MOOCs and Open Education: Implications for Higher Education [R/OL]. http://publications.cetis.ac.uk/2013/667,2013.3.

[8] 徐贺兵\&赵鹤.国内移动语言学习研究现状与问题—— 基于研究理论、研究性质和研究对象视角 [J].《长江大学学报》2015(1):56-59. 
[9] 景飞龙\&秦杰. 国外移动技术辅助语言学习研究热点与前沿的可视化探析 [J]. 《中国远程教育》2019( 1):79-85.

[10] 李思索\&高原.移动技术辅助外语教学对英语词汇习得有效性的实证研究[J].《外语界》2016(4):7381.

[11] 李祖君.元认知策略指导下英语词汇的教与学[J].《教学与管理》2014(1): 109-111.

[12] 马俊波.M-learning 与外语教学的对接:从CALL到MALL[J].《外语电化教学》2007(5):30

[13] 冯建军.《现代教育学》.[南京]: 南京师范大学出版社, 2007.

[14] 平和光\&杜亚丽.“互联网 + 教育”:机遇、挑战与对策.[J].《现代教育管理》2016(1):13-18.

[15] 胡茶娟\&沈春蕾. 国内移动英语学习研究的现状分析与思考——基于国内十年（20042014年）研究的分析 [J].《中国远程教育》2015(10):15-20.

[16] 高敏\&吴介军\&姚静红.基于手机的 M-Learning 系统研究与设计.[J]《现代教育技术》2008(8):93-96.

[17] 杨丽芳.移动学习在大学英语词汇学习中的应用.[J]《外语电化教学》2012(4):54-58.

\section{AUTHORS' BIOGRAPHY}

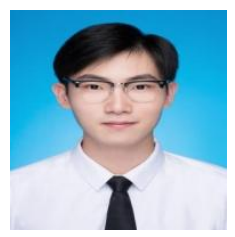

Chengyuan Wu was born in Taizhou, China in 1998. He is a third-year English major in Zhejiang Ocean University.

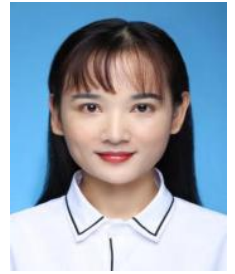

XiaoXu Chen was born in Zhoushan, China in 1986. She received her M.A. degree in English language and literature in Shanghai International Studies University, China. She is a lecturer in the School of Foreign Languages, Zhejiang Ocean University, China. Her current researches focus on British and American culture.

Citation: Chengyuan Wu, Xiaoxu Chen. "A Study on Effectiveness of Vocabulary Apps---Based on MALL Theory". International Journal of Humanities Social Sciences and Education (IJHSSE), vol. 6, no 7, $2019, \mathrm{pp}$. 83-91. doi: http://dx.doi.org/10.20431/2349-0381.0607009.

Copyright: () 2019 Authors. This is an open-access article distributed under the terms of the Creative Commons Attribution License, which permits unrestricted use, distribution, and reproduction in any medium, provided the original author and source are credited. 